\title{
Visões antagônicas sobre o ideário da Liga Internacional pela Educação Nova em dois manuais de História da Educação publicados no Brasil na década de 1930
}

\author{
(Contrasting perspectives on the ideology of the New Education \\ Fellowship in two History of Education manuals published in Brazil \\ in the 1930s)
}

Décio GATTI JÚNIOR*

Universidade Federal de Uberlândia

\begin{abstract}
RESUMO: Abordamos a forma como experiências e ideias de educadores vinculados à Liga Internacional pela Educação Nova foram tomadas em dois importantes manuais de História da Educação publicados no Brasil na década de 1930. 0 primeiro, Noções de História da Educação, de Afrânio Peixoto, em 1933; o segundo, Educação. História da Educação. Problemas Actuaes, das Madres Peeters e Cooman, em 1937. Em ambos, sob perspectivas antagônicas, há intensa presença da temática da Educação Nova, o que se vinculava, de um lado, ao esforço de construir uma República democrática, por meio de reformas educacionais e, de outro, à busca da manutenção da relevância católica na sociedade brasileira. Em um ponto, porém, a narrativa de ambos os manuais converge - na objeção, por razões diferentes, as iniciativas educacionais da Rússia soviética. Conclui-se pela centralidade adquirida pelo movimento internacional da Educação Nova nos debates educacionais brasileiros das primeiras décadas do Século XX.
\end{abstract}

PALAVRAS-CHAVE: História. Educação Nova. Manuais disciplinares. Liberalismo. Catolicismo.

ABSTRACT: The article examines the treatment of the experiences and ideas of educators associated with the New Education Fellowship in two important History of Education manuals published in Brazil in the 1930s: Noções de História da Educação [Concepts of History of Education] (1933) by Afrânio Peixoto, and Educação (História da Pedagogia): Problemas Actuais [Education (History of Pedagogy): Current Issues] (1937) by Mothers Superior Peeters and Cooman. Though written from completely different perspectives, the theme of New Education receives extensive attention in both: in the former, associated with the effort to build a democratic republic through educational reform; and in the latter, identified with the attempt to preserve the role of the Catholic church in Brazilian society. Where the two manuals do coincide is in their objection (for differing reasons) to the educational initiatives of soviet Russia. The research highlights the centrality of the inter- 
national New Education movement in Brazilian educational debates in the early decades of the twentieth century.

KEYWORDS: history; New Education; manuals; liberalism; Catholicism

\section{Introdução}

Neste artigo abordamos o ideário do movimento internacional de renovação educacional, especialmente, após a criação da Liga Internacional pela Educação Nova (LIEN), em 1921, que foi um esforço importante de difusão de iniciativas e de ideias inovadoras, por meio de uma série de atividades que agregavam educadores de todo 0 mundo $\mathrm{e}$ impulsionavam empreendimentos de reforma educacional. ${ }^{1}$

Nessa direção, a bibliografia brasileira sobre a temática tem afirmado a existência de relações entre os articuladores da LIEN e educadores brasileiros que estiveram à frente do movimento renovador nacional entre as décadas de 1920 e 1930. Relações que se objetivaram por meio de viagens ao exterior de intelectuais brasileiros, vinda para realização de conferências e seminários de representantes de associações e instituições internacionais ao Brasil, circulação de impressos educacionais provenientes de diferentes nações etc. ${ }^{2}$

Todavia, apesar de nos beneficiarmos da leitura destes importantes trabalhos, muitos dos quais pioneiros, nossa abordagem recaíra sobre as narrativas sobre Educação Nova presentes em dois importantes manuais de História da Educação publicados no Brasil na década de 1930, os quais alcançaram grande difusão em território nacional, com presença, sobretudo, nas salas de aula das escolas normais brasileiras. ${ }^{3}$

\footnotetext{
* Apoio/support: CNPq; Fapemig

${ }^{1}$ Sobre 0 ideário do movimento internacional de renovação educacional e sobre a LIEN, sugere-se a leitura de: Antón Costa Rico, A construción do coñecemento pedagóxico. Antecedentes e desenvolvementos no século XX (Santiago de Compostela: Universidade, Servizo de Publicacións e Intercambio Científico, 2009); Laurent Gutierrez, "La Ligue internationale pour l'Éducation nouvelle". Spirale. no.45. (2010), https://www.persee.fr/ doc/spira_0994-3722_2010_num_45_1_1155, (Consultado em 15 de setembro de 2020).

${ }^{2}$ Mais informações em: Marta M.C. Carvalho, "0 Manifesto e ao Liga Internacional pela Educação Nova", em Manifesto dos pioneiros da educação. Um legado educacional em debate, ed. Maria C. Xavier (Rio de Janeiro: Editora FGV, 2004), 147-181; Diana G. Vidal e Rafaela S. Rabelo, "A criação de Institutos de Educação no Brasil como parte de uma história conectada da formação de professores", Cadernos de História da Educação 18, no.1 (2019), https://doi.org/10.14393/che-v18n1-2019-12. (Consultado em 22 de setembro de 2020).

${ }^{3}$ Sobre os manuais de História da Educação, sugere-se a leitura de: Maria H.C. Bastos, "Uma biografia dos manuais de História da Educação adotados no Brasil (1860-1950)", em Anais do VI Congresso Luso-Brasileiro de História da Educação. (Uberlândia: Universidade Federal de Uberlândia, 2006), 334-349; Marta M.C. Carvalho e Décio Gatti Jr., coord., O Ensino de História da Educação (Espírito Santo: Edufes, 2011); Décio Gatti Jr.; Carlos Monarcha; Maria H.C. Bastos, coord.coord., O Ensino de História da Educação em Perspectiva Internacional (Uberlândia: Edufu, 2009); Clarice Nunes. "Ensino e historiografia da educação. Problematização de uma hipótese", Revista Brasileira de Educação 02, no.1 (1996), http://anped.tempsite.ws/novo_portal/rbe/rbedigital/ RBDE01/RBDE01_07_CLARICE_NUNES.pdf (Consultado em 15 de setembro de 2020). Especificamente na temática sobre a Educação Nova, podemos citar: Carlos Monarcha, "Práticas de escrita da História da Educação: 0 tema da Escola Nova nos manuais de autores brasileiros", em 0 ensino de História da Educação
} 
Tratam-se do livro Noções de História da Educação, de Afrânio Peixoto, publicado em 1933, pela Cia. Editora Nacional, e do livro Educação. História da Pedagogia. Problemas Actuaes, das Madres Peeters e Cooman, publicado em 1937, pela Cia Melhoramentos de S. Paulo. Em ambos os manuais, a temática da Educação Nova é abundante, todavia, com perspectivas de análise antagônicas, o que se coaduna ao ambiente conflituoso que existia no Brasil na década de 1930.

\section{Contexto histórico-educacional nas décadas de 1920 e 1930}

0 movimento internacional em torno da renovação educacional, com antecedentes que remontam ao final do Século XIX, ganhou maior densidade e consistência a partir da década de 1920, quando um conjunto de investimentos resultou na veiculação de um ideário mais coeso, por meio de congressos internacionais, organização de associações, publicação de periódicos e realização de viagens de intercâmbio. ${ }^{4}$

No Brasil na mesma época, devido ao crescimento do republicanismo, ganhou força uma série de iniciativas, o que incluiu, estudos, investigações, intercâmbios internacionais e proposições legais reformistas que levaram a estruturação do campo educacional, cuja expressão destacada seria a criação em 1924 da Associação Brasileira de Educação $(\mathrm{ABE})$, inicialmente, integrada por liberais e católicos, em uma concordata que não se estendeu por muito tempo. ${ }^{5}$

As dissenções entre liberais e católicos avolumaram-se no campo político e educacional, por meio da veiculação de propostas antagônicas: de um lado, um discurso sobre a necessidade de republicanizar a República, com tom crítico prevalente e busca da difusão da escolarização de igual qualidade para todos; de outro, uma narrativa que buscava restaurar o papel central da Igreja na sociedade, com poder político e exclusividade na oferta educacional.

Nessa direção, a ruptura com a Primeira República, por meio da Revolução de 1930, evidenciaria as diferenças entre liberais e católicos, com ambos os grupos em busca de influenciar o poder instituído. Em relação ao novo regime, os católicos já tinham conseguido instituir nas escolas públicas estatais 0 ensino religioso, com oferta obrigatória e matrícula facultativa. Os liberais, por seu turno, tinham expressado sua agenda de reformas por meio da publicação de um importante manifesto em 1932. Para Marta Carvalho,

em perspectiva internacional, ed. Décio Gatti Jr.; Carlos Monarcha; Maria H.C. Bastos, (Uberlândia/MG: Edufu. 2009), 65-93.

${ }^{4}$ Entre 1921 e 1936, são organizados pela Liga Internacional pela Educação Nova, uma série de congressos, em diferentes cidades europeias, relacionados ao esforço de difusão do ideário escolanovista. Além disso, surgem importantes periódicos relacionados ao reformismo educativo, destacadamente: The New Era (Beatrice Ensor); Pour L'Êre Nouvelle (Ferrière); Das Werdenta Zeitalter (Elizabeth Rotten). No que se refere às viagens de intercâmbio, por exemplo, Ferrière, Pierón, Fauconnet estiveram no Brasil entre as décadas de 1920 e 1930, bem como Lourenço Filho, Anísio Teixeira e uma série de educadores brasileiros na mesma época estiveram na Europa e nos Estados Unidos.

${ }^{5}$ Sobre a ABE, ver: Marta M.C. Carvalho. Molde nacional e fôrma cívica: higiene, moral e trabalho no projeto da Associação Brasileira de Educação, 1924-1931 (Bragança Paulista: Edusf, 1998). 
A grande novidade do Manifesto dos pioneiros da educação nova foi, sem dúvida, o seu impacto na redefinição do campo dos debates educacionais. 0 que, antes, na década de 1920, era convergência em torno da "causa cívico educacional" passa a explicitar-se como confronto de posições: escola única x escola dual; ensino público x ensino particular, ensino leigo x ensino religioso. [...] a tônica do Manifesto será a defesa de uma escola única, pública, leiga e gratuita. ${ }^{6}$

$\mathrm{Na}$ arena educacional, ambos os grupos promoveram iniciativas associativas, bem como mantiveram esforços editoriais, com publicação de periódicos e livros destinados ao público em geral, mas, também, ao público escolar, notadamente, das escolas normais. Nessa direção é importante lembrar que a liberdade de ensino dava a tônica para as instituições escolares, com 0 Estado, as confissões religiosas e a sociedade civil a promover 0 ensino escolar, o que se estendia à Escola Normal, responsável pela formação de professores, para todas as escolas primárias.

\section{Sobre 0 autor de Noções de História da Educação, 1933: Afrânio Peixoto7}

Afrânio Peixoto nasceu em 1876, na Bahia e faleceu em 1947 no Rio de Janeiro. Estudou na Faculdade de Medicina da Bahia entre os 15 e 21 anos, na qual defendeu a tese "Epilepsia e crime", com apelo a medicamentação do crime, o que, posteriormente, seria estendido à educação. Foi preparador de Medicina Legal na Faculdade de Medicina da Bahia e exerceu a docência de Medicina Pública na Faculdade de Direito da Bahia. Em 1902, seguiu para o Rio de Janeiro, onde se consolidaria profissionalmente, por meio do ingresso na Academia Nacional de Medicina, da publicação de artigos no periódico Brasil Médico, do exercício do cargo de direção do Hospital Nacional dos Alienados, da docência de Medicina Legal e Higiene na Faculdade de Medicina do Rio de Janeiro, da criação e direção do Serviço de Medicina Legal, da docência de Medicina Pública na Faculdade de Direito do Rio de Janeiro, da direção da Escola Normal do Distrito Federal e do exercício do cargo de Diretor-Geral Instrução Pública.

Entre 1924 e 1930, exerceu o cargo de deputado federal pela Bahia e em 1932 era catedrático da Faculdade de Direito do Rio de Janeiro. No campo da Medicina Legal trabalhou com os conceitos de eugenia e higiene. Afrânio Peixoto foi um dos signatários do Manifesto dos Pioneiros da Educação Nova de 1932, mediante pedido direto de Fernando

\footnotetext{
${ }^{6}$ Marta M.C. Carvalho, "0 Manifesto e ao Liga Internacional pela Educação Nova", em Manifesto dos pioneiros da educação. Um legado educacional em debate, ed. Maria C. Xavier (Rio de Janeiro: Editora FGV, 2004) 147181.

${ }^{7}$ A bibliografia sobre Afrânio Peixoto e as Noções de História da Educação é extensa, destacadamente: José G. Gondra, "Genealogia como exercício de contramemória: Afrânio Peixoto e a emergência da escola (1932-1942)", Cadernos de História da Educação 19, no.3. (2020), https://doi.org/10.14393/che-v19n2-2020-7 (Consultado em 15 de setembro de 2020); Carlos E. Vieira e Roberlayne 0.B. Roballo, "História e História da Educação no projeto de formação de professores na década de 30 no Brasil: problematizando as Noções de Afrânio Peixoto", Inter-ação 32, no.2, 2007, https://doi.org/10.5216/ia.v32i2.3049 (Consultado em 15 de setembro de 2020); Heloísa H.P. Rocha, "Recordação para professoras: a História da Educação Brasileira narrada por Afrânio Peixoto", em Dos arquivos à escrita da História: a educação brasileira entre o Império e a República, ed. José G. Gondra (Bragança Paulista: Edusf, 2001) 11-36. No que se refere especificamente aos dados biográficos de Afrânio Peixoto, utilizamos: Eliane M.T. Lopes. "Júlio Afrânio Peixoto", em Dicionário de Educadores no Brasil, ed. Maria L.A. Fávero; Jader M. Britto (Rio de Janeiro: Editora UFRJ, 2002) 659-663.
} 
Visões antagônicas sobre o ideário da Liga Internacional pela Educação Nova em dois manuais de História da Educação...

de Azevedo, bem como foi o primeiro reitor da Universidade do Distrito Federal, cargo do qual se exonerou em solidariedade a Anísio Teixeira. ${ }^{8}$

\section{Os antecedentes da Escola Nova em Noções de História da Educação de Afrânio Peixoto}

A obra Noções de História da Educação foi publicada em 1933, um ano após a divulgação do Manifesto dos Pioneiros da Educação Nova. Sua primeira edição possui 282 páginas, com ilustrações, no formato $14 \times 21 \mathrm{~cm}$, capa dura e sobrecapa. Na sobrecapa somos informados que a obra integra a Bibliotheca Pedagogica Brasileira, sob a direcção de Fernando de Azevedo, Série III, Actualidades Pedagogicas, Volume V, com publicação pela Companhia Editora Nacional de S.Paul0 ${ }^{9}$. Na quarta capa, constam, para efeito de divulgação, os volumes publicados anteriormente na série, com os seguintes autores: Fernando de Azevedo, Dewey, Anísio Teixeira e Claparède.

As características das Noções de História da Educação enquadram-se perfeitamente no escopo geral de obras publicadas em um momento de institucionalização da formação de professores, principalmente, por meio de escolas normais, mais, em alguma medida, também, no ensino superior, conforme consta do prefácio da obra.

\footnotetext{
Hoje em dia a 'globalização' da cultura mal suporta o arteficio, indidatico, das monografias especializadas, instrutivas talvez, certamente não educativas, por inapetentes e fatigantes. Era preferível uma perspectiva panoramica, a campos microscópicos meramente documentais. A finalidade era menos histórica, que educacional, mais da evolução de algumas ideias, do que da cronologia de alguns factos: as datas e os nomes na história são referencias úteis, mas o essencial é o caminho percorrido, no espaço e no tempo. ${ }^{10}$
}

Em termos de estrutura narrativa, a influência das obras estrangeiras publicadas anteriormente é visível, por meio da percepção do predomínio da periodização da História da Civilização e da ênfase didática, destacadamente, pela inserção no início de cada um dos capítulos de efemérides detalhadas que foram nomeados pelo autor sincronismos.

Naquilo que antecede o capítulo relacionado à Escola Nova, a ênfase recai sobre: Locke e Rousseau; Pestalozzi, Froebel e Herbart; Comte, Stuart Mill, Spencer e Bain; Mann, James e Dewey. Também aparecem nomes vinculados à América Latina, Sarmiento e Varella. No que se refere ao Brasil, constam capítulos sobre Anchieta (jesuítas), Pombal, Monarquia (1822-1889) e República (1889-1932), com destaque para alguns educadores brasileiros.

\footnotetext{
${ }^{8}$ A Universidade do Distrito Federal foi uma tentativa modernização dos processos de formação de professores no Brasil, sob a liderança de Anísio Teixeira, em consonância com ideário escolanovista internacional, que sofreu grave revés na Era Vargas.

${ }^{9}$ A esse respeito, ver: Maria R.A. Toledo, "A Companhia Editora Nacional e a política de editar coleções (19251980): entre a formação do leitor e o mercado de livros", em 0 Impresso no Brasil, ed. Márcia Abreu e Aníbal Bragança (São Paulo: Editora da Unesp, 2010) 136-157.

${ }^{10}$ Afrânio Peixoto. Noções de História da Educação (São Paulo, Cia. Editora Nacional, 1933) 7.
} 


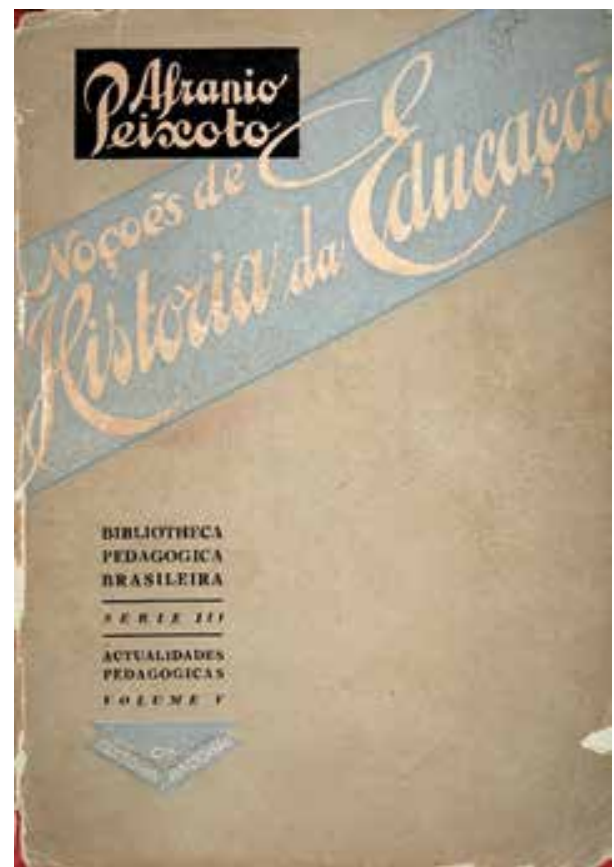

Capa da primeira edição de Noções de História da Educação, de Afrânio Peixoto (1933). Fonte: Acervo do autor.

No sincronismo que consta da parte inicial dos capítulos relacionados ao Brasil, Afrânio Peixoto destaca eventos que assinalam o caráter progressista assumido pela sociedade, bibliografia e legislação em torno da educação nacional, o que inclui: 1854, Inauguração dos telégrafos; 1855, Início da Estrada de Ferro Central; 1858, Liceu de Artes e Ofícios do Rio de Janeiro; 1867, A instrução pública no Brasil, de Liberato Barroso; 1871, Lei do Ventre Livre; 1872, Cabo submarino para a Europa e Rio da Prata; 1873, Projeto de conferências pedagógicas; 1879, Lei da liberdade de ensino; 1880, Escola Normal do Município da Corte; 1883, Parecer de Rui Barbosa. Exposição Pedagógica; 1888, Abolição da Escravidão; 1889, Proclamação da República. "L ínstruction publique ao BrésiP', de Pires de Almeida; 1891, Código do Ensino; 1906, "A Educação Nacional”, de José Verissimo; 1915, As promessas e os resultados da pedagogia moderna, de Miguel Calmon; 1916, 0 Ensino público no Congresso Nacional, de Primitivo Moacyr; 1917, 0 Brasil e a educação popular, de Carneiro Leão; 1923, Ensinar a ensinar, de Afrânio Peixoto; 1930, Revolução; 1932, Manifesto Educacional: pela escola leiga, obrigatória, única, activa e progressiva.

Na abordagem do período monárquico brasileiro, de 1822 a 1889, Afrânio Peixoto, destaca a adoção, em 1823, do método lancasteriano, bem como relata seu fracasso. Adota um tomo eminentemente crítico, por exemplo, no comentário sobre um importante parecer: 
Rui Barbosa, num parecer, como diante de doente grave, o Brasil desamparado de saúde moral, que só a educação consegue, falava em linguagem médica, "da fase diatética de um mal, que chegou ao extremo de sua invasão, paralisando nos centros diretores as forças de reação e a própria consciência da enfermidade. [...] 0 ensino público está á orla do limite possível a uma nação que se presume livre e civilizada; e que há decadência, em vez de progresso; é que somos um povo de analfabetos e que a massa deles, se decresce, é numa proporção desesperadoramente lenta; é que a instrução academica está longe do nível scientifico desta idade; é que a instrução secundária oferece ao ensino superior uma mocidade cada vez menos preparada para o receber" (p. 232-233).

Além disso, Afrânio Peixoto assinala os pontos de progresso visível que estão contidos no parecer de Rui Barbosa, o que inclui a defesa da liberdade de ensino, da laicidade da escola pública, da instrução obrigatória, da preparação de mestres para a escola primária na escola normal, da criação de um Museu Pedagógico Nacional, da fundação de uma Diretoria Geral de Instrução Pública, da criação do Conselho Superior de Instrução Nacional, do estabelecimento de políticas relacionadas à higiene das escolas e da implantação da estatística da instrução. 0 teor crítico da narrativa de Afrânio Peixoto é reiterado na afirmação sobre o referido parecer de que essa "maravilha de sciência e de consciencia, é inútil dizer, não teve éco no Parlamento; admiraram-na, mas não a compreenderam, e, menos, a atenderam" (p.234).

$\mathrm{Na}$ abordagem do período republicano, iniciado em 1889, Afrânio Peixoto prossegue com tom muito crítico, assinalando dados alarmantes quanto ao analfabetismo, da ordem de $60 \%$ da população entre 1872 e 1920, o que denota insucesso das políticas republicanas. Para ele:

nessa inútil defesa contra a ignorancia: a condição vital da democracia, que é a instrução popular; 0 rendimento economico, das despesas com o ensino; a mentira cívica do sufrágio universal, a injustiça criminosa do júri; a incapacidade de defender a pátria contra o perigo interno e externo, sem a cultura mental e moral da escola; a necessidade da escola democrática, escola "única", que reúne todas as classes da sociedade, fundindo-as, fazendo, á-parte dos regionalistas bairristas, a alma do brasileiro, capaz de amar e servir a grande causa da Pátria comum... Tudo, tudo improficuamente (p. 239).

No final da parte dedicada ao Brasil foram elencados educadores brasileiros proeminentes, entre os quais destacamos apenas alguns nomes do campo progressista: Abilio Cesar Borges, médico, que fundou o Ginásio Baiano, onde estudaram Castro Alves e Rui Barbosa, um lugar avançado e que buscava adotar métodos novos e práticas modernas de ensino; Joaquim José de Menezes Vieira, também médico, que fundou colégio e incorporou melhoramentos decorrentes de viagens à Europa, bem como criou em 1890, 0 Pedagogium e manteve a Escola do Domingo, com cursos de educação literária para operários; Rui Barbosa, bacharel em Direito, grande orador das causas liberais, que traduziu a Primeira lição de coisas, de Calkins, em 1886, bem como redigiu os pareceres que resumem, segundo Afrânio Peixoto, a "pedagogia mais nova e liberal do seu tempo, nos paizes mais adiantados, Estados Unidos, Alemanha, França, Inglaterra, com admirável lucidez e erudição" (p. 248). 


\section{A Escola Nova em Noções de História da Educação de Afrânio Peixoto}

É no último capítulo que Afrânio Peixoto aborda a Escola Nova, corolário das iniciativas fecundas anteriores e uma esperança de mudança e melhoria da educação nacional em sintonia com a evolução social e educacional que se passa nos países de referência, com destaque para alguns eventos e feitos logo no sincronismo apresentado.

No que se refere as iniciativas institucionais, 0 autor destacou a criação em 1899 do Bureau international de l'école nouvelle, por iniciativa de Ferrière. No que se refere às reformas escolares foram enfatizadas, pela ordem: 1922-25: Prússia e estados alemães; 1923, Gentile (Itália), Krupskaia (Rússia); Bérard (França); 1929, A Reforma do ensino no Distrito Federal, por Fernando de Azevedo (Brasil).

Quanto as iniciativas e experiências escolares destacou, entre outras: 1889, Abbotsholme (Reddie); 1896, Escola Laboratório da Universidade de Chicago (Dewey); 1898, Landerziehungsheime (Lietz); 1899, L'Ecole des Roches (Desmoulins); 1901, Instituto de retardados de Uccle (Decroly); 1904, Dalton Laboratory Plan (Parkhurst); 1921, Escola Regional de Merity (D. Amanda Alvaro Alberto).

No que tange às obras publicadas no período, destacou, entre outras: 1898, La mesure en psychologie individuelle (Binet); 1916, Democracy and Education (Dewey); 1921, Educational Psychologie (Thorndike); 1922, Education et Sociologie (Durkheim); 1927, A Escola Nova (Lourenço Filho); 1928, Pedagogia Proletaria (Pistrak, Punkevich e Chatowsky); 1928, Aspectos americanos da Educação (Anísio Teixeira); 1929, A Reforma do ensino no Distrito Federal (Fernando de Azevedo); 1930, Introdução ao Estudo da Escola Nova (Lourenço Filho); 1931, L'école sur mesure a la mesure du maitre (Ferrière).

Por fim, houve destaque para a veiculação no Brasil do Manifesto Educacional (pela escola ativa, progressiva, laica, gratuita, obrigatória e a coeducação), em 1932, com vinte três signatários, entre os principais, Azevedo, Teixeira, Lourenço Filho e o próprio Afrânio Peixoto. ${ }^{11}$

É evidente que este quadro de eventos denota uma proximidade com o movimento internacional pela Educação Nova, bem como a participação na formulação nacional de movimento de mesma natureza e, ainda que não seja mencionada diretamente, há indícios consistentes de aproximação com os preceitos emanados da LIEN, tanto por meio da menção de experiências escolares que lhe são próximas, como pelo elenco de obras de autores significativos para o empreendimento internacional e sua associação ao movimento nacional.

\footnotetext{
${ }^{11}$ Sobre 0 Manifesto de 1932, ver: Maria C. Xavier, coord. Manifesto dos pioneiros da educação. Um legado educacional em debate (Rio de Janeiro: Editora FGV, 2004); Luís A.M. Alves, "República e Educação: dos princípios da Escola Nova ao Manifesto dos Pioneiros da Educação", Revista da Faculdade de Letras - HISTÓRIA 11 (2010), http://ojs.letras.up.pt/index.php/historia/article/view/3654 (Consultado em 25 de setembro de 2020); Carlos R.J. Cury e Célio de Cunha, coord, "0 Manifesto Educador: os pioneiros 80 anos depois", Revista Brasileira de Estudos Pedagógicos 96, no. especial (2015), http://rbep.inep.gov.br/ojs3/index.php/rbep/issue/ view/484 (Consultado em 25 de setembro de 2020).
} 
Visões antagônicas sobre o ideário da Liga Internacional pela Educação Nova em dois manuais de História da Educação...

Para Afrânio Peixoto, a escola nova propugna pela escola única, ativa e progressista, em franca oposição ao domínio da Igreja sobre os processos de escolarização das novas gerações, mas, também, opõe-se ao domínio do Estado sobre a educação, com busca da vinculação entre indivíduo e sociedade na escola, por meio do exercício da liberdade. Para ele:

\begin{abstract}
Não o individuo a se desenvolver dentro do vaso fechado da Igreja ou do Estado, mas a se desenvolver livremente, na sociedade de que é parte, órgão de um organismo, sociedade cuja civilização se transforma, se muda, cada vez menos injusta e violenta, mais econômica e liberal para qual o educando, sempre educado, tem de viver, colaborando. A escola é um prefácio da vida. A educação na escola é a suma de métodos sociais resumidos e selecionados, com que a sociedade prepara, nas crianças, os homens activos, dignos, honestos, bons, de que precisa, para viver felizmente. A educação é a "saude" da sociedade, promovida desde a infância (p.253)
\end{abstract}

Os progressos das ciências biológicas são o ponto de partida de uma compreensão do universo e da natureza, sem ilusões, na dinâmica funcional de ambos, "donde uma fisiologia, uma psicologia e por tanto uma ética, condicionados á vida; pela civilização que se transforma, changing civilization, com maquinismo industrial, com a economia do trabalho, com 0 advento da democracia, tecnica e real... (p. 253-254), 0 que está em relação com o ponto de chegada almejado:

\begin{abstract}
Homogeneização da sociedade, reunindo na educação as castas, as classes exploradoras e exploradas, dominantes e dominadas, sacerdotais e leigas, nobres e plebéas, ricas e pobres, na escola única, que estandartiza socialmente; é a paz interna ou espiritual, separada a crença ou mesmo a política, da escola leiga e popular, para o out-side das igrejas ou dos parlamentos, com a escola neutra; é a paz externa, inculcada no aluno a solidariedade humana, pela colaboração, pela sintonia espiritual, vencendo os particularismos agressivos das pátrias imperialistas e guerreiras: sociabilização pela educação, obra educativa, intencional, para ser conseguida, na escola activa, escola nova (p.254).
\end{abstract}

É então na dinâmica da vida, horizonte de evolução e progresso, que se consolida a escola progressiva, na qual a inteligência resulta da ação interessada, por meio da passagem das coisas à razão, com a passagem do eixo da escola da autoridade do mestre para a iniciativa do aluno. Ideias estas que expressam influências de Spencer e Dewey, o que encontra correspondência com 0 texto do Manifesto de 1932, no qual as ideias destes autores também são citadas.

Após estas digressões iniciais, Afrânio Peixoto apresenta, a partir de Lourenço Filho (1929), os experimentos escolares precursores da Escola Nova, o que faz com apontamentos sobre cada um deles, desde a origem na Inglaterra, por meio das "new-school" até a difusão em outros países, destacadamente: Public Schools inglesas; Escola Nova de Reddie, Inglaterra; Escola des Roches de Demoulins, França (inspirada nas escolas novas da Inglaterra); Land-Erziehungsheime de Leitz, Alemanha (inspirada em Abbotsholme, Inglaterra); Escola Nova de Wineken (colaborador de Leitz), Alemanha; Escola Nova de Geheeb, 1909, Alemanha; a Arbeitsschule de Kerschensteiner, Alemanha.

0 autor assinala também a emergência de sistemas independentes, tais como: 0 Dalton Laboratory Plan, de Parkhust, nos Estados Unidos; as iniciativas de Washburne, 
também nos Estados Unidos (próximas do Dalton Plan e influenciadas pelo ensino sob medida, preconizado por Claparède); Cousinet, na França; Gentile, na Itália fascista; a Escola Serena de Radice (Itália), que inspirou a Reforma Gentile e aderiu às escolas de Franchetti, discípula de Leitz; e outros ensaios: Ligthart (Holanda), Rabindranath Tagore (India), Gary, Wirth-Sain/Platoon-System (Estados Unidos).

No que se refere à Rússia, Afrânio Peixoto menciona criticamente as escolas de Lunatcharky, de Sobeleff e de Krupskaia, por meio da afirmação de que nestas concepções as crianças pertencem ao Estado e é preciso fazer delas comunistas, o que seria uma escola ativa com duas submissões ideológicas próprias: marxismo revolucionário e ateísmo materialista.

No Brasil, destacou as iniciativas de D. Amanda Alvaro Alberto, por meio da Escola Regional do Merity, no Rio de Janeiro, uma adaptação rural, com trabalho em comunidade e valorização dos interesses naturais das crianças e cooperação da família; Lourenço Filho, na Escola Rio Branco, em São Paulo, uma escola nova de projetos à Dewey; Fernando de Azevedo, por meio da institucionalização da escola nova na reforma do ensino no Rio de Janeiro (1926-1930); e, Anísio Teixeira, diretor atual da instrução no Rio de Janeiro (implantação da escola progressiva).

É importante mencionar que no elenco de eventos precursores, consta também a criação em 1899, do Bureau international des écoles nouvelles, por Ferrière, em Genebra, na Suíça, visto por Afrânio Peixoto como resultado da expansão mundial da Escola Nova, o que abrangia, para além da Inglaterra e França, também, Rússia, Japão, Suécia, Estados Unidos e ainda outros países.

Por fim, Afrânio Peixoto, aborda autores que ele considera que colaboraram para 0 processo de sistematização da metodologia e da teoria da escola nova, ativa e progressiva, o que inclui Montessori (Itália), Decroly (Bélgica) e Dewey (Estados Unidos).

Sobre Montessori, destacou a formação em Medicina e os estudos sobre os anormais, com consequências sobre as crianças normais, por meio da análise dos métodos que seriam úteis aos primeiros e ainda mais para os segundos. Ressaltou a criação da Casa dei Bambini, escola sem predominância de disciplina formal inútil e com valorização da dimensão lúdica do ensino. Em seguida, discorre sobre Decroly, que também era formado em Medicina, com estudos sobre os anormais, com destaque para a criação da Escola da rua de Ermitage, em Bruxelas, à qual avalia como uma escola que seria uma adaptação da escola tradicional à escola de amanhã, inspirada em Dewey, Kilpatrick e Ferrière, com corte mais biológico e menos socializante. Observa ainda que Decroly tinha falecido recentemente, em 1932, mas que ele tinha realizado palestras em diferentes países, entre os quais: Estados Unidos, Bolívia, Argentina, Uruguai, Espanha, nos quais deixou inúmeros admiradores e discípulos. Sobre Dewey, último sistematizador analisado, assevera a união original de ideias filosóficas e pragmáticas, ao meio americano, aos ensaios de Chicago e à experiencia de ensino na Universidade de Columbia. Resumidamente, Peixoto afirma que em Dewey: 
a soma total dos processos por meio dos quais a sociedade infunde nas gerações novas seus poderes, capacidades e ideias, com o fim de assegurar a propria existencia e evolução. Toda educação é social, sem sujeição, mas dependência, órgão a desenvolver, a criança, para um organismo, a sociedade. A escola é uma sociedade embrionária. Unidade de pensamento e de ação realiza nela o trabalho, suscitado por uma situação problemática. Educação funcional, humanizada pelo trabalho em comunidade, cuja eficácia social é a finalidade. Sendo a vida uma sequencia de projectos, isto é, uma sucessão de actos com um fim previsto, começar a resolvê-los, na escola [...] A ação traz a idéia. "Aprender, vivendo primeiro o que se aprende. Aprender pela vida e atravez da vida". "A criança é o centro da escola e não 0 mestre" (p. 265).

A escolha de Dewey para finalizar o livro não parece ocasional, mas, possivelmente, carrega 0 espírito que preside a narrativa de Afrânio Peixoto, ao unir a dimensão de evolução social e a tarefa educacional em relação as novas gerações, o que anuncia os termos de sua conclusão na qual consta que a "educação, na escola, se resuma numa fórmula breve: deve ser o 'noviciado' da sociedade” (p. 265).

\section{Sobre as autoras de Educação. História da Educação. Problemas Actuaes, 1937: Madres Peeters e Cooman ${ }^{12}$}

As Irmãs de Santo André são uma antiga congregação católica, fundada em 1231, na cidade de Tournai, atualmente na Bélgica, que foi criada por iniciativa de duas Irmãs que, após fazerem votos de pobreza, decidiram abrir uma estalagem em Saint Nicolas du Bruille, com 0 intuito de hospedar romeiros pobres que se dirigiam à Terra Santa. Muito depois, em 1837, a congregação passou a seguir as regras da Constituição de Santo Inácio, tornando-se missionárias da Companhia de Jesus.

Em 1913, a Madre Superiora Geral das Religiosas de Santo André recebeu uma carta do bispo de São Carlos do Pinhal (São Paulo, Brasil), D. José Marcondes Homem de Mello, que solicitou a abertura de colégios em sua diocese. Após análise favorável, a Madre Superiora encaminhou para o Brasil, em 1914, a Madre Lúcia Maria Doyle e as Irmãs Francisca Peeters ${ }^{13}$, Lucy Chopinet, Ana Schockaert e Alice Corradini, que chegaram neste mesmo ano e iniciaram as atividades do colégio na cidade paulista de Jaboticabal.

\footnotetext{
${ }^{12}$ As informações sobre as Madres Peeters e Cooman e sobre a obra Educação. História da Pedagogia. Problemas Actuaes foram buscadas em: Anamaria G.B. Freitas e Jorge C. Nascimento, "As madres da historiografia educacional: o manual de Peeters e Cooman", em Anais do IV Congresso Brasileiro de História da Educação, (Goiânia: Editora da UCG, 2006), https://ri.ufs.br/handle/riufs/1070 (Consultado em 22 de setembro de 2020); Luiz A. Oliveira; Antonio M. Sartori, "Pequena História da Educação: a influência do ideal cristão católico na formação de professores do ensino primário", em Pesquisas em Educação e História da Educação: um diálogo entre saberes, ed. Dyeinne C.T. et al., coord. (Rio de Janeiro: Ed. Multifoco, 2017), 64-88; Sandra R.F. Oliveira; Décio Gatti Jr., "A reação católica e a formação de professores no Brasil: os manuais disciplinares Noções de Sociologia e Educação. História da pedagogia. Problemas actuaes das Madres Peeters e Cooman (1935-1971)", Revista Brasileira de História da Educação 18 (2018), http://dx.doi. org/10.4025/rbhe.v18.2018.e041 (Consultado em 22 de setembro de 2020).

${ }^{13}$ Elizabeth Peeters nasceu em Tournai, Bélgica, em 1876. Faleceu em 1973, em Jaboticabal, São Paulo, Brasil. Sétima filha de uma grande família católica. Seus estudos foram realizados na cidade natal. Aos domingos, na escola dominical de sua comunidade, colaborava na alfabetização de adultos. Em Louvain, na Bélgica, ingressou no curso superior. Em seguida, esteve na llha de Jersey, por tempo suficiente para aprender o inglês. Buscou a Congregação das Irmãs de Santo André, na qual iniciou sua formação religiosa aos 19 anos de idade,
} 
Entre 1925 e 1928, solicitaram e tiveram aprovada a concessão da Escola Normal, na qual Madre Francisca Peeters lecionava diferentes disciplinas e secretariava a escola. Madre Maria Augusta de Cooman, por seu turno, veio para Brasil em 1916, no quarto grupo de Irmãs, sendo que atuava também em diversas disciplinas e funções administrativas no colégio. ${ }^{14}$

Em 1935, Madre Peeters teve publicado o manual Noções de Sociologia. Depois, em coautoria com Madre Cooman, em 1937, publicaram o manual Educação. História da Pedagogia. Problemas Actuaes, todavia, a coautoria ficou restrita a primeira parte da obra, História da Pedagogia. A segunda parte, Problemas Actuaes, foi escrita apenas pela Madre Peeters.

\section{Sobre a primeira parte do livro das Madres Peeters e Cooman: História da Educação}

A primeira edição de Educação. História da Pedagogia. Problemas Actuaes foi publicada em 1937, com capa dura, no formato 14x21cm, 194 páginas e sem ilustrações. $\mathrm{Na}$ capa da primeira edição, constava a imagem de S. Ignatius de Loyola. Na quarta capa, constava a divulgação de outras obras publicadas pela Cia. Melhoramentos de S. Paulo. Da vertente religiosa, por exemplo: Noções de Sociologia, da Madre Francisca Peeters; A Educação na Escola, de D. Joaquim Silverio de Souza; Philosophia - Pedagogia - Religião, de Lucio José dos Santos. Do campo liberal e escolanovista, no qual aparecem nomes vinculados à LIEN, por exemplo: Psychologia Experimental, de Henri Piéron; A Escola e a Phychologia Experimental, de Claparède; Vida e Educação, de John Dewey.

Antecedem o texto propriamente da obra o IMPRIMATUR, concedido pelo ArcebispoBispo diocesano de Jaboticabal, que era um importante instrumento de controle eclesiástico sobre aquilo que se poderia publicar no âmbito católico. Em seguida, consta 0 prefácio do padre Lucio José dos Santos, no qual ele advoga que a verdade do conhecimento não está de fato na ciência, mas na forma como tomamos o verdadeiro espirito que a precede, sendo que a Pedagogia não pode afastar-se de uma concepção de mundo que negue suas relações com a Filosofia e com a Religião. Condena o esforço de apagar a influência religiosa, por meio da seguinte afirmação:

continuando sua formação intelectual. Nesse período, recebeu o nome pelo qual seria conhecida: Francisca Peeters. Consagrada a Deus pelos votos religiosos em 1897, inicialmente, dedicou-se ao ensino no colégio de Tournai, depois veio para o Brasil.

${ }^{14}$ Madeleine de Cooman nasceu em Grammont, na Bélgica, em 1878. Faleceu em 1963 na cidade de Jaboticabal. Era de uma família profundamente cristã. Iniciou seus estudos na cidade natal, em escola particular mantida pela Congregação religiosa das Beneditinas, prosseguindo em Tournai, com as Irmãs de Santo André. Cursou a Escola Normal para preparar-se ao magistério. Depois de dois anos passados junto à família, voltou para Tournai, onde pediu admissão para a vida religiosa e, em 1899, aos 21 anos de idade, recebeu o nome de Maria Augusta, iniciando o período de formação. Fez os votos religiosos em 16 de setembro de 1901. 


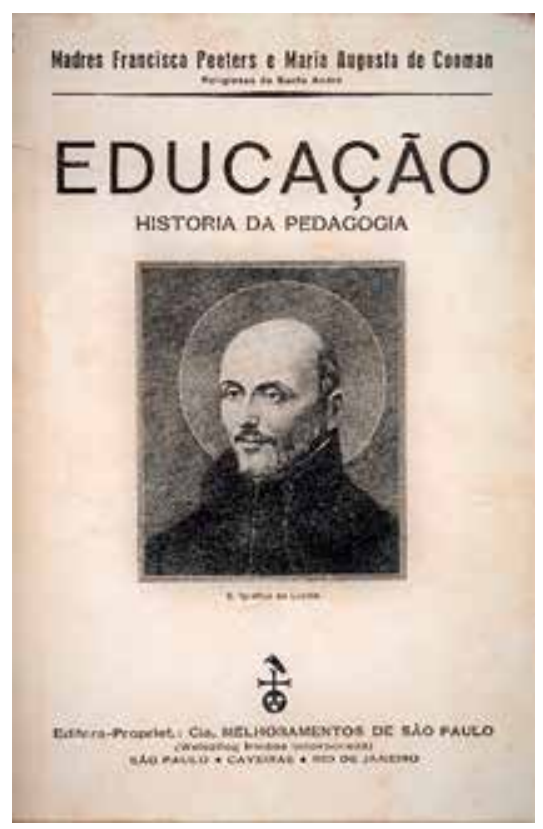

Capa da $1^{\mathrm{a}}$. edição de Educação. História da Pedagogia. Problemas Actuaes, das Madres Peeters e Cooman (1937). Fonte: Acervo do autor.

\begin{abstract}
Em outros vae ainda, no horror á Historia, uma preocupação sectaria: apagar o passado é abolir a influencia christã. [...] Em um congresso de professores primarios, em França, propoz-se francamente a abolição da Historia. Datemos da revolução franzesa a Historia Universal: dizia-se, há tempos. Comecemos pela victoria do Communismo na Russia: prefere-se hoje. ${ }^{15}$
\end{abstract}

0 autor do prefácio elogia o livro das Madres Peeters e Cooman, dado que elas valorizaram 0 catolicismo e defendem a pedagogia perene, por meio de uma narrativa imparcial. Porém, é difícil dar razão ao prefaciador, sobretudo pelo caráter combativo que predomina no livro, conforme podemos perceber já no texto de apresentação das autoras: "0 grande peccado dos catholicos hodiernos é não saberem conquistar o seu logar ao sole deixar as calumnias e a conspiração do silencio attribuir ao campo adverso todas as iniciativas fecundas $\mathrm{e}$ as benemerencias educacionaes". ${ }^{16}$

No conteúdo que antecede ao tratamento da temática da Escola Ativa, as autoras, sempre sob tom crítico, abordam a educação como disciplina em Locke, a tendência naturalista (Rousseau), o estatismo e o nacionalismo do Século XIX (Fichte e Hegel), a

\footnotetext{
${ }^{15}$ Lucio J. Santos, "Prefácio", em Educação. História da Pedagogia. Problemas Actuaes, Madres Francisca Peeters e Maria Augusta Cooman (São Paulo: Cia. Melhoramentos, 1937) 5.

${ }^{16}$ Madres Francisca Peeters e Maria Augusta Cooman, Educação. História da Pedagogia. Problemas Actuaes (São Paulo: Cia. Melhoramentos, 1937).
} 
tendência psicológica da educação (Pestalozzi, Herbart, Froebel), o desenvolvimento da Psicologia experimental em sua relação com a educação na França, Bélgica, Alemanha, Estados Unidos, Inglaterra e Rússia e o naturalismo científico (Comte e Spencer). Sobre estes temas, contrariamente a Afrânio Peixoto, advogam que:

\begin{abstract}
a obra do Protestantismo e do Renascimento se fazia sorrateiramente. Do livre exame, brotou insensivelmente 0 abandono da Revelação. Cada um se fazia a sua religião, e a autonomia do pensamento se tornara aos poucos um dogma. [...] 0 individuo é para seus apologistas, a fonte de tudo. Toda a grandeza nasce do desabrochar completo do individuo. Religião, moral, cultura são obra humana. Tudo quanto contraria a personalidade é um mal: tradição, familia, Estado, Igreja são coisas secundarias que devem inclinar-se perante 0 individuo (p.110).
\end{abstract}

Consideravam erro grave o pressuposto escolanovista de que a sociedade seria a única realidade e que a História seria um processo de evolução social, no qual a educação estaria a serviço dos interesses da coletividade, por meio da cooperação no trabalho escolar, da democratização e da organização escolar com a colaboração dos alunos. Nessa direção, Dewey seria 0 "representante mais legitimo da corrente radical-socialista" (p.110), para quem a formulação dos juízos dependem de suas consequências práticas e a escola deveria acompanhar três revoluções: intelectual (ciências físicas e naturais); industrial (técnica moderna); social (democracia). Na mesma linha, no cenário alemão, discordam de Natorp, sobretudo da ideia da existência apenas da religião da Humanidade e de sua defesa da supressão do ensino religioso, com exclusividade do Estado em matéria de Educação.

Sobre Kerschensteiner afirmam que durante "toda sua vida [...] foi um mendigo de ideal, sem jamais encontrar nada que 0 satisfizesse, porque nunca pensou em buscaIo na religião" (p.112). Todavia, a crítica mais contundente foi desferida em relação à Durkheim: "na Sociologia a 'mystica' social de Durkheim, a 'sociolatria', a sua pedagogia; 0 individuo é relegado na sombra: a alma, os destinos eternos, Deus, a psychologia individual, a moral individual, as aspirações mais elevadas do homem, tudo deve ser sacrificado á sociedade" (p.113).

Após considerarem erráticas boa parte das ideias formuladas desde a Renascença, as autoras avançam para o tema da Escola Ativa, em um capítulo inteiramente a ela dedicado. Iniciam pelos Estados Unidos, com a consideração do pioneirismo de Mann, que consideram um entusiasta da educação popular e repleto de ideias comunistas. Defensor de ideias problemáticas, tais como: a de que a ignorância seria um crime contra 0 a República democrática; 0 ensino religioso seria um dogmatismo despótico dos professores e uma escravidão para os alunos; a coeducação assinalaria o respeito mútuo entre os sexos; os compêndios escolares deveriam ser reduzidos ao mínimo necessário.

Para as autoras, Mann advogava que as escolas públicas seriam o melhor meio de evitar a criminalidade, porém, em tom crítico vaticinavam que contrariamente "multiplicaram-se os 'gangsters', criminosos de toda especie, os divorciados, os especuladores deshonestos, etc." (p.114). A propósito, as autoras aproveitam para criticar Afrânio Peixoto, pois que para ele, "a America, é uma boa escola activa", diante do que elas objetam: "Talvez haja quem deseje menos atividade e mais honestidade moral" (p.114). 
William James, que elas consideram outro inspirador da Escola Ativa, toma erroneamente a criança como um pacote de instintos, que se necessita fortalecer a atenção, com geração da associação, de modo a despertar e entreter o interesse. Nele, as aquisições formam 0 sujeito e, por meio do entrecruzar de ideias associadas, forma-se a personalidade. Todavia, objetam que a "philosophia do pragmatismo é falsa confundindo o verdadeiro e 0 útil: faz da utilidade, não um sinal da verdade, mas a condição dela; destróe assim 0 fundamento da moral. 0 concreto supplanta a lei interior e eterna. 0 Catholicismo é mais do que o pragmatismo, a religião da acção e da vontade, mas sem os erros delle" (p.114).

Sobre Dewey, reiteram a ideia de que se trata de um radical-socialista, para o qual o pensamento seria um meio de realizar projetos, sem finalidade exterior à criança, com uma visão de que a educação seria a perpétua adaptação a uma situação presente. $A$ organização da escola, por seu turno, deveria ser pautada pela organização social, com a democracia social nela introduzida, por meio do fomento à cooperação. Assim, a "collaboração será a alma da educação. 0 mestre e os livros são secundarios" (p.115).

Kilpatrick, por sua vez, cuja obra Educação para uma Civilização em Mudança teria encontrado grande difusão no Brasil, seria um continuador de Dewey, o que repetem em relação à Thorndike. No que se refere ao Dalton Plan, de Parkhurst ressaltam o apelo a autoinstrução, o emprego do livro de objetivos e de soluções, com a supressão da aula, do horário e da graduação do ensino, temas que eram caros à educação católica.

Em relação à Alemanha, consideram Kerschensteiner moderado, ao conjugar atividade manual e vida espiritual, afirmando que a "sua areligião não é tão completa como a de Dewey" (p.116), mas, em relação à Gurlitt, são taxativas: "Estamos com elle em pleno communismo" (p.116), o que se repete em relação à sueca Ellen Key que consideram extremamente materialista e revolucionária, para a qual: os "paes e as mães têm tanto direito e poder para impor leis ás crianças como para traçar trajectoria aos astros" (p.117). 0 veredito das autoras sobre Key: "Fala da grandeza e majestade da criança deante da qual devem curvar-se os paes. Emfim prepara as vias para a bolchevização das escolas (p.117).

Wineken também sofre forte objeção das autoras, por propugnar uma escola com autodireção pelos alunos, na qual professores e alunos fossem camaradas, coeducação e, na qual, estivesse negada a inclinação religiosa das crianças, com a abolição do ensino religioso. Advogam que para Wineken seria "um crime contra a sociedade deixar á família o cuidado da educação: a família educa com fins egoístas, e não cogita do amor á collectividade" (p.117).

Quanto ao que ocorre na França e na Bélgica, consideram ser diferente do que se passava nos países anglo-saxônicos e germânicos, dado que para as autoras eles estariam menos inclinados as mudanças advindas da industrialização e da ênfase democrática, com maior apego a tradição e permanência de bases psicológicas e filosóficas.

Sobre Claparède explicam que ele busca dar significação biológica aos processos mentais, com 0 interesse como alavanca da educação. Para ele, a escola tradicional 
estaria ancorada em atos sem causa, com recompensas e castigos. Deveríamos tomar a criança no centro dos programas e dos métodos, de modo a consolidar a compreensão da educação como forma de adaptação progressiva dos processos mentais a certas ações determinadas por desejos, com fortalecimento da ideia da disciplina interior em substituição a exterior. Todavia, as autoras objetam que a "questão é de saber como nascerá 0 interesse em certas disciplinas necessarias e raras vezes do gosto da criança, se não se despertar este interesse dum modo artificial? [...] Provocar um interesse espontaneo é uma contradicção nos termos" (p.118).

Aproximam Ferrière de outros escolanovistas, na defesa da coeducação, da educação intelectual de dentro para fora, na formação de uma cultura geral, no ensino baseado em fatos e experiências e na atividade da criança. Para elas, "Ferrière descreve a escola activa como um internato familiar, situado no campo, e onde a experiencia pessoal serve de base á educação intellectual, mediante, principalmente, o emprego de trabalhos manuais, e á educação moral pelo systema de autonomia dos alumnos" (p.119). Objetam, porém, que Ferrière inspirou-se em uma concepção filosófica e mesmo poética advindas de Abbotsholm na Inglaterra e da Landrziehungsheim na Alemanha, mas com 0 erro em se manter "pessoalmente infenso a toda idéa religiosa" (p.119).

Sobre a École des Roches, fundada em 1899, consideram-na positivamente, dado que, para elas souberam aplicar o sistema de escola ativa, com a moderação do espirito cristão. Para as autoras, a escola de Demolins, obedeceria ao plano de Ferrière, mas com espírito religioso, sem admitir a coeducação. Há capelães e serviço religioso diário, bem como consta a educação religiosa, para além da educação física, artística, trabalhos manuais, educação intelectual, formação moral e social. Elogiam o propósito de reunir "numa harmoniosa synthese os thesouros duma tradição secular e o benefico fermento da educação nova" (p.120), mas, também há críticas, pois "a École des Roches não é feita nos moldes das reformas sociaes apregoadas pela maior parte dos seus protagonistas; de mais a mais só pode servir para as famílias abastadas, e não corresponde ao typo das escolas democráticas, apesar da vontade sinceramente affirmada de não reconhecer distincções sociaes entre os seus alumnos" (p.120).

Sobre Decroly, ressaltam sua formação em Medicina, sobretudo, em neurologia e neuropatologia, que fomentaram o interesse dele na elevação do nível mental dos deserdados morais, com a fundação de instituições para anormais e, depois, para meninos normais na Rua de l'Ermitage, na qual ocorriam cursos ao ar livre e em locais organizados na forma de laboratórios. Criticam, porém, as "condições dispendiosas e impraticáveis em escolas mesmo oficiaes, e muito mais em grande numero de instituições livres" (p. 121). Asseveram, porém, que 0 ensino por centros de interesse não era incompatível com 0 ensino religioso.

Do seu methodo aperfeiçoado e criteriosamente modificado, podem educadores inspirar-se largamente porque não contém certas exagerações nefastas a respeito da independencia dos escolares. [...] 0 reformador belga separa-se pois da Escola activa em dois pontos: admite que há verdades e disciplinas necessarias para todos e que devem ser ensinadas collectivamente. [...] Seja qual fôr 0 destino das theorias de Decroly, -- sua obra merece os louvores de quem se interessa pela sorte 
dos anormais e elle terá contribuído dum modo poderoso para melhorar a situação desses infelizes (p.121).

Consideram que algumas ideias da italiana Maria Montessori, também médica, seriam adequadas à escola maternal. Sua "Casa dei Bambini”, de 1907, diferentemente de Fröbel, teria ensino individualizado. Para elas, Montessori defenderia a liberdade como base para a disciplina e para a atividade pessoal, com a formação do espírito de fora para dentro. Seu material instrucional estaria vinculado a essa ideia, com papel ativo da criança que deveria ser capaz de encontrar as causas de sucessos e insucessos sozinha. Porém, para as autoras:

a auto-educação começada tão cedo offerece o perigo de formar espirito presumidos e arrogantes. Num Congresso de Educação tido em Marselha, alguns chegaram a dizer que, se os alumnos vindos das escolas Montessori se distinguiam dos outros, era sobretudo pela insolencia. Emfim o systema de jogos, excellente na primeira infância, deve reduzir-se cada vez mais na escola primaria propriamente dita; é um abuso querer-se applicar o methodo a este typo (p.122-3).

Sobre a Rússia Soviética fazem críticas duras, desde a inspiração nas ideias nefastas de Tolstoi, que fundou a Yasnaia Poliana (uma escola sem regulamento, sem disciplina, sem mestres impostos aos alunos), com a memória do autor "cultuada pelos bolchevistas" (p.123). Para elas, a pedagogia soviética seria materialista, ateísta militante, com a escola sob monopólio completo do Estado e comunista. A propaganda soviética seria 0 fundamento das escolas do partido, que formavam os dirigentes, com conhecimentos ancorados no marxismo, no materialismo didático e na doutrina comunista. Asseveram que há "escolas normaes sem-Deus destinadas aos mestres do ensino primário e secundário" (p.124).

A respeito do Brasil dão notícia da existência de um movimento a favor das escolas novas nos últimos dez anos, porém, advertem que não há uma escola nova, mas muitas, que, para elas possuem alguns traços comuns, pois que se baseiam

$$
\begin{aligned}
& \text { num optimismo naturalista a respeito da rectidão moral da criança, e sobre uma negação consciente } \\
& \text { ou inconsciente da queda original. Todas ou quasi todas revestem-se de um idealismo exagerado, } \\
& \text { confiando-se demasiado no critério dos educandos no domínio do interesse. A finalidade da educaçã̃o } \\
& \text { é falseada e reduzida a uma série de adaptações a situações actuaes, sem perceber-se o fim supremo } \\
& \text { (p.125). }
\end{aligned}
$$

Os dois capítulos seguintes são dedicados a reação espiritualista em relação ao escolanovismo, com a apresentação da "educação social moderada", com análises sobre: Willmann (Igreja como ponto de apoio para a reforma social); Paulsen (tradição como ponto vital da pedagogia sã); Foerster (a vontade do indivíduo deve submeter-se a Deus e crítico da moral naturalista, socialista, nietzcheana e cientifica). Também mencionam Kidd (consciência do dever, espírito de sacrifício, abnegação, bens supraindividuais); Monsenhor Spalding (contagiar o caráter, comoção de um ideal, trabalho e sofrimento, domínio de si, disciplina, papel educativo da família); S. João Bosco, fundador dos salesianos e das Filhas de Maria Auxiliadora (caridade, vigilância contínua e benevolência); 
Dupanloup (a única liberdade é a disciplina interior e a criança é a imagem de Deus); Newman e Mercier (portadores da verdadeira ideia de universidade e defensores do verdadeiro espirito universitário, no qual se estabelece a ordem e a síntese). No final, há um apêndice, no qual as autoras comentam sobre a educação da mulher ao longo do tempo.

No último capítulo da primeira parte, abordam a história da educação no Brasil. Tratam da presença dos jesuítas, com destaque para Anchieta, bem como do ensino desde a expulsão dos jesuítas, em 1759, até a independência, em 1822. Sobre o período monárquico, que se estende de 1822 a 1889, destacam a adesão ao método lancasteriano, em 1823, quando aproveitam para provocar os escolanovistas: "Durante 20 annos o Methodo Lancasteriano gozou da mesma fama que a Escola nova está fruindo entre nós" (p.153).

Constatam que na década de 1870 houve percepção dos enormes problemas da instrução pública no país e resumem o conteúdo dos pareceres de Rui Barbosa, o qual "pleiteou em setembro de 1882 a liberdade de ensino, a laicidade da Escola publica, e a instrucção obrigatória, obedecendo ás normas dadas pela maçonaria internacional. Mas as medidas que apontava não tiveram echo no Parlamento" (p.155).

Da República, proclamada em 1889, assinalam a criação do Ministério da Instrucção Publica, em 1894 e informam sobre a existência de 67,2\% de brasileiros que não sabiam ler. Destacam o fato de que a Constituição de 1891 teria banido 0 ensino religioso. Lançam atenção para o problema do analfabetismo, mas, diferentemente do ideário reformador, apresentam a seguinte proposição:

Se ao menos, ao lado de ligeira bagagem de conhecimentos se dessem ao povo ensinamentos religiosos e moraes, elle seria talvez um pouco mais ignorante, mas seria educado, o que é o principal" (p.155). Novamente, elas objetam os pioneiros da educação nova, com a alegação de que a "illusão de crear uma nação forte pelo facto de ter diminuído o numero de analphabetos é das que difficilmente se desarraigarão nos tempos actuaes, mas que nem por isso deixam de ser illusões (p.155-6).

Por fim, as autoras objetaram inteiramente aquilo que nomearam "novas correntes" na pedagogia brasileira, por não terem nada genuinamente brasileiro, com inspiração nos Estados Unidos (Dewey e Kilpatrick), por meio da afirmação da impossibilidade de adaptação pela diferença de contextos. Com relação a Lourenço Filho, liderança do campo educacional renovador no Brasil, advogam:

Entre os pedagogos que mais se esforçaram para lançar o Brasil na corrente actual, destaca-se 0 talentoso e erudito Snr. Lourenço Filho, ex-director do Ensino em S.Paulo, e actualmente Director do Departamento Nacional de Educação. Seu livro sobre a "Escola Nova" demonstra uma capacidade invulgar, que, constitue um titulo para a admiração de quem se interessa nas coisas da educação ainda que não partilha das generosas illusões provenientes aliás dum espirito elevado e idealista (p.156-7).

\section{Sobre a segunda parte do livro: Problemas Actuaes, de autoria exclusiva da Madre Peeters}

Em Um punhado de problemas educacionaes, segunda parte do livro, Madre Peeters abordou cinco problemas específicos relacionados à Educação e a escola. 0 primeiro 
referia-se à escala de valores, que iniciou pelo tema do corpo, com forte crítica aos disparates dos naturalistas, especialmente, de Spencer, na defesa da ideia de sermos todos bons animais. Para ela, o "corpo é, depois da alma, a obra mais nobre do Creador; é 0 domicilio do espirito, o Templo da Trindade adorável, e tal é o respeito que nossa religião professa para esse sanctuario que até depois da morte, o rodeia com sua veneração (p.159). Assim, defende escolas abertas à luz, com boa ventilação e asseadas, nas quais prevaleça a vida regrada e austera, com combate a gulodice e a preguiça. Defende ainda que se trave "uma guerra sem tregoas ao cinema que mantem no organismo infantil uma hypertensão nervosa em extremo damnosa, tanto para o desabrochar normal do corpo como para o equilíbrio mental" (p.160).

Quanto ao cérebro, advoga que erudição não é inteligência, com entulhamento de conteúdo que não deixa espaço para a reflexão. 0 saber não seria o fim mais importante da educação, mas, sim, "a transformação interior do homem, o governo de si, pela submissão ao governo de Deus; em suma, a formação do caracter pela formação da consciencia" (p.163). Para Madre Peeters, a queda original trouxe o desequilíbrio ao ser humano e

\begin{abstract}
sómente a religião [...] pode empolgar os homens até 0 amago do seu sêr, e levá-los a preencher sempre e em todo logar o seu dever, com o pleno sentimento da sua responsabilidade. Que ideal podem apresentar á criança os systemas modernos de moral? A Sociedade? Mas a Sociedade é sobremodo anarchica; a sua "moral" evolue constantemente. 0 respeito de si? Mas que diz a criança, e mesmo 0 adulto este respeito de si, quando ninguém 0 vê, 0 que a tentação 0 allicia violentamente? Em nome de quem a moral laica nos pode mandar sacrificar as nossas inclinações ao próximo, ao Estado, a sociedade? Vencer a colera, o egoísmo, a preguiça, a sensualidade? Que nos promete esta moral em troca da nossa renuncia? A personalidade de Christo que nos offerece a Pedagogia Catholica é indispensável na educação: é um ideal vivo; é Elle que a criança aprende a amar, amando o seu próximo e fazendoIhe bem; é d'elle que se haurem a força, na Eucharistia, na oração, na contemplação de sua Belleza incomparável; a convicção que Elle nos vê, nos ama, nos conduz, ao termo que é o nosso Tudo e a nossa felicidade sem fim, tudo isso é insubstituível fonte de formação moral, e de elevação do caracter (p.164).
\end{abstract}

Nessa direção, o educador deveria ter um papel determinante, especialmente, na primeira infância, tornando-se inútil "pela disciplina interior que se vem adquirindo; sem o que, pode-se permanecer annos a fio no melhor dos educandários, e sahir de lá, como se entrou, sem rumo, sem bussola, sem força (p.165).

Sobre o segundo problema, que se refere ao eixo da Escola, iniciou pela afirmação de que a criança se tornou um ídolo no Século XX, com ideias que devem ser combatidas:

Ferrière indigna-se contra a doutrina "desmoralizante que acostuma a criança a buscar fora de si a palavra de ordem". Claparède nos adverte que não pode haver na escola actividade imposta. "A criança é perfeita nos dizem Gurlitt e Ellen Key. 0 que se deve fazer é deixá-la desenvolver-se livremente". "A vida é uma deusa, exclama a Dra. Montessori: estimulá-la, desenvolvê-la livremente, tal é a missão do educador" [...] Excusado é continuar as citações: todas fendem o mesmo som desafinado (p.166-7).

Para a autora, é insuperável 0 amor à infância dos educadores católicos, sendo a criança uma fonte ainda pura, que reflete à perfeição a graça divina e conquistou a predileção do Mestre. Na sequência, apresentou críticas diretas a alguns renovadores: 
Não, senhora Ellen Key, a criança não é perfeita: nesses olhinhos, nesses gestos, nessas attitudes, nessas reações provocadas pelos mil incidentes da vida escolar, qual o mestre vigilante que não divisou manifestações dos sete peccados capitães? [...]

Não, Snr., Dra. Montessori, a vida não é uma deusa: não basta viver para progredir. A vida mais punjante pode conduzir todos os desmandos. $E$ as indoles mais ricas em recursos precisam mais do que as outras ser disciplinadas e "podadas". [...] Nossos paes nos legaram 0 seu temperamento, suas inclinações, mas não as suas virtudes: nesse ponto a civilização tem de se refazer individualmente: cada um de nós deve restabelecer em si o equilíbrio que o peccado rompeu. Tarefa tremenda e que nenhuma criança, deixada a si será capaz de realizar.[...]

Por isso, Senhor Ferrière, concordando com applausos com a vossa indignação contra uma educação que acostumaria o educando a buscar fora de si a palavra de ordem, perguntamos-vos o que advirá se, se nos tenros anos, 0 acostumamos a buscar em si, i.é, nos instinctos que o dominam, e não no livre arbítrio ainda em formação esta mesma palavra de ordem... (p.167-8).

Sobre os mestres, a autora considera que os reformadores em suas caricaturas da escola tradicional sempre os criticaram, o que considera natural, pois "os reformadores precisam ridicularizar e enviar ao pelourinho os systemas que querem substituir..." (p.169) e, complementa: "não assistimos na politica a este jogo divertido?..." (p.169). Para ela, no entanto, prevalece a fala de Cristo "Que vossa luz brilhe diante destes pequeninos, a fim de que vendo as vossas obras glorifiquem vosso Pae que está no Céu" (p.170).

Finaliza com a afirmação que é em Deus que está o eixo da escola, a verdadeira autoridade, 0 alfa e 0 ômega, pois nenhum "homem tem 0 direito de mandar aos seus semelhantes. Só o tem Aquelle que é o Auctor. Quem manda deve lembrar-se sempre que é só o porta-voz dos dictames interiores da consciência, voz de Deus na alma dos homens (p.170).

No terceiro problema, sobre psicologismo ou psicologia, critica a mera observação, pois "é preciso utilizar-se das suas observações para que o nosso estudo não seja um estudo de diletante esteril e vão (p.175). Em verdade, é preciso que exista entusiasmo naquilo que se faz, pois, sem "paixão, sem enthusiasmo, nada de grande se faz no mundo: é o reino da mediocridade. Os santos todos foram apaixonados da gloria divina [...]. A paixão [...] é um immenso thesouro quando nos arrasta para 0 que constitue 0 ideal de vida sobrenatural: a santidade" (p.176). Em seguida, há um apêndice, com o documento "Esboço de psychograma julgado útil para o conhecimento dos educandos", uma ficha biométrica, com os itens: corpo, memoria, inteligência, vida afetiva, vida volitiva, vida social, vida religiosa.

As escolas ativas são o tema do quarto e do quinto problema. Para Madre Peeters, a escola religiosa adota métodos ativos, mas distantes das práticas espontaneístas propostas pelos escolanovistas, com valorização de contéudos que levem em conta 0 sobrenatural e as verdades perenes. Considera que até que se encontre "quem nos prove a superioridade dos methodos novos, continuaremos na concepção 'antiquada' da escola “activa'” (p.182).

Na conclusão desta segunda parte do livro, Madre Peeters reafirma a proeminência da educação católica e reforça 0 caráter combativo, por meio de reiterada desqualificação dos reformadores escolanovistas, conforme se pode examinar a seguir: 
Doutrinas que se alicerçam sobre a Verdade eterna, sobre a perenidade das especificidades humanas; sobre a continuidade histórica [...] podem desafiar os séculos vindouros. [...] a Pedagogia catholica assistirá impávida ao enterro das "Educações para uma civilização em mudança". Podemos e devemos remoçar as fachadas do edifício, mas não derrubar uma só pedra de sua construção. [...] Da fermentação de idéas novas, das "heresias pedagogicas modernas", resulta um chaos e uma confusão que não deixam de impressionar quem se occupa seriamente do assumpto (p.187).

\section{Considerações finais}

0 ideário educacional reformador das primeiras décadas do século XX, em especial, a partir do movimento internacional pela Educação Nova, no qual se destaca a criação da LIEN em 1921, era compartilhado por educadores e reformadores brasileiros, mas, também fomentou forte reação, especialmente do catolicismo da época.

É interessante observar que o público normalista brasileiro estava separado; uma parte frequentava escolas normais vinculadas ao Estado e, outra parte, frequentava escolas normais católicas, o que era possível devido à liberdade de ensino vigente. Porém, mediante programas de ensino formulados pelo Estado, que, todavia, não garantiam igual abordagem dos conteúdos. Também ficou claro que uma mesma editora, publicava livros e manuais com autores de perspectivas antagônicas, de modo a atingir mais leitores e, portanto, melhorar seus resultados comerciais.

Uma questão que exemplifica essa diferença de visões é 0 analfabetismo. Em Afrânio Peixoto é um problema a ser resolvido com urgência, como base para a existência verdadeira da República democrática. Para as Madres Peeters e Cooman, seriam educados em escolas apenas aqueles que fosse possivel e, para os demais, bastaria a fé católica, inclusive, nomeavam de ilusão pedagógica, a obsessão pela escolarização dos reformadores educacionais.

Há também silenciamentos, por exemplo, acerca do movimento de reação espiritualista no manual de Afrânio Peixoto, o que parece demonstrar uma diferença importante de estratégia narrativa, pois as Madres Peeters e Cooman elencam personagens importantes da Educação Nova, para poderem objetar suas ideias, a partir do ponto de vista católico. Enquanto a narrativa de Afrânio Peixoto expressa uma linha continua de evolução e progresso, sem enfatizar as reações contrárias.

$\mathrm{Na}$ abordagem da educação na Rússia soviética, todavia, ainda que por motivações diferentes, a objeção está presente em ambos. Para Afrânio Peixoto, defensor de uma República Democrática, seria um erro considerar que as crianças pertencessem ao Estado e submeter a escola ativa as ideologias do marxismo revolucionário e do ateísmo materialista. Para as Madres Peeters e Cooman, religiosas e defensoras da filosofia perene, a pedagogia dos soviéticos comportaria erros graves: materialismo, monopólio da educação pelo Estado e ateísmo militante.

Sem dúvida, há outros aspectos que poderiam ser analisados, dada a riqueza do tema e das fontes, mas, devemos concluir, com a esperança de termos colaborado para um melhor entendimento da forma como o movimento internacional da Educação Nova 
e, particularmente, a partir da LIEN, foram recepcionados no Brasil, por meio da adesão de alguns e da objeção de outros, mas, em todos os casos, longe da indiferença, o que denota a relevância das propostas de renovação educacional da época.

\section{Bibliografia}

Alves, Luís A.M. "República e Educação: dos princípios da Escola Nova ao Manifesto dos Pioneiros da Educação". Revista da Faculdade de Letras - HISTÓRIA 11 (2010), http://ojs.letras.up.pt/index.php/historia/article/view/3654 (Consultado em 25 de setembro de 2020).

Bastos, Maria H.C. "Uma Biografia dos Manuais de História da Educação adotados no Brasil (1860-1950)". Em Anais do VI Congresso Luso-Brasileiro de História da Educação, 334-349. Uberlândia/MG: Edufu. 2006.

Carvalho, Marta M.C. Molde nacional e fôrma cívica: higiene, moral e trabalho no projeto da Associação Brasileira de Educação (1924-1931). Bragança Paulista/SP: Edusf. 1998.

Carvalho, Marta M.C. "0 Manifesto e ao Liga Internacional pela Educação Nova". Em Manifesto dos pioneiros da educação. Um legado educacional em debate, editado por Maria do Carmo Xavier. 147-181. Rio de Janeiro: Editora FGV. 2004.

Carvalho, Marta M.C. e Gatti JR., Décio, coord. O Ensino de História da Educação. Espírito Santo: Edufes. 2011.

Costa Rico, Antón. A construción do coñecemento pedagóxico. Antecedentes e desenvolvimentos no século XX. Santiago de Compostela: Universidade, Servizo de Publicacións e Intercambio Científico. 2009.

Cury, Carlos R.J. e Cunha, Célio de, coord. "0 Manifesto Educador: os pioneiros 80 anos depois". Revista Brasileira de Estudos Pedagógicos 96, no. especial (2015), http:// rbep.inep.gov.br/ojs3/index.php/rbep/issue/view/484 (Consultado em 25 de setembro de 2020).

Freitas, Anamaria G.B. e Nascimento, Jorge C. "As madres da historiografia educacional: o manual de Peeters e Cooman". Em Anais do IV Congresso Brasileiro de História da Educação, 1-10. Goiânia: Editora da UCG. 2006, https://ri.ufs.br/handle/riufs/1070 (Consultado em 22 de setembro de 2020).

Gatti Jr., Décio; Monarcha, Carlos; Bastos, Maria H.C., coord. O Ensino de História da Educação em Perspectiva Internacional. Uberlândia/MG: Edufu, 2009. 
Gondra, José G. "Genealogia como exercício de contramemória: Afrânio Peixoto e a emergência da escola (1932-1942)". Cadernos de História da Educação 19, no.3. 2020, https://doi.org/10.14393/che-v19n2-2020-7 (Consultado em 15 de setembro de 2020).

Gutierrez, Laurent. "La Ligue internationale pour l'Éducation nouvelle”. Spirale. no.45. 2010, https://www.persee.fr/doc/spira_0994-3722_2010_num_45_1_1155 (Consultado em 15 de setembro de 2020).

Lopes, Eliane M.T. “Júlio Afrânio Peixoto”. Em Dicionário de Educadores no Brasil, editado por Maria L. A. Fávero e Jader M. Britto. 659-663. Rio de Janeiro: Editora da UFRJ, 2002.

Monarcha, Carlos. "Práticas de escrita da História da Educação: 0 tema da Escola Nova nos manuais de autores brasileiros". Em 0 ensino de História da Educação em perspectiva internacional, editado por Décio Gatti Jr.; Carlos Monarcha; Maria H.C. Bastos. Uberlândia/MG: Edufu. 2009.

Nunes, Clarice. "Ensino e historiografia da educação. Problematização de uma hipótese". Revista Brasileira de Educação 02, nº.1 (1996), https://anped.org.br/sites/default/ files/rbe/files/rbe_01.pdf. (Consultado em 15 de setembro de 2020).

Oliveira, Luiz A. e Sartori, Antonio M. "Pequena História da Educação: a influência do ideal cristão católico na formação de professores do ensino primário". Em Pesquisas em Educação e História da Educação: um diálogo entre saberes, editado por C.T. Dyeinne et al., 64-88, coord. Rio de Janeiro: Ed. Multifoco, 2017.

Oliveira, Sandra R.F.; Gatti Jr, Décio. "A reação católica e a formação de professores no Brasil: os manuais disciplinares Noções de Sociologia e Educação. História da pedagogia. Problemas actuaes das Madres Peeters e Cooman (1935-1971)". Revista Brasileira de História da Educação 18, (2018), http://dx.doi.org/10.4025/ rbhe.v18.2018.e041 (Consultado em 22 de setembro de 2020).

Peeters, Madre Francisca e Coomann, Madre Maria Augusta. Educação. História da Pedagogia. Problemas Actuaes. São Paulo: Cia. Melhoramentos. 1937.

Peixoto, Afrânio. Noções de História da Educação. São Paulo. Cia. Editora Nacional. 1933.

Rocha, Heloísa H.P., "Recordação para professoras: a História da Educação Brasileira narrada por Afrânio Peixoto". Em Dos arquivos à escrita da História: a educação brasileira entre o Império e a República, editado por José G. Gondra, 11-36, Bragança Paulista: Edusf, 2001. 
Santos, Lucio J. "Prefácio". Em Educação. História da Pedagogia. Problemas Actuaes, editado pelas Madres Francisca Peeters e Maria Augusta Cooman. 5-10. São PauIo: Cia. Melhoramentos, 1937.

Toledo, Maria R.A. “A Companhia Editora Nacional e a política de editar coleções (19251980): entre a formação do leitor e o mercado de livros". Em 0 Impresso no Brasil, editado por Márcia Abreu e Aníbal Bragança. 136-157. São Paulo: Edunesp. 2010.

Vidal, Diana G. e Rabelo, Rafaela S. "A criação de Institutos de Educação no Brasil como parte de uma história conectada da formação de professores". Cadernos de História da Educação 18, nº.1. (2019), https://doi.org/10.14393/che-v18n1-2019-12 (Consultado em 22 de setembro de 2020).

Vieira, Carlos E., Roballo, Roberlayne 0.B. "História e História da Educação no projeto de formação de professores na década de 30 no Brasil: problematizando as Noções de Afrânio Peixoto". Inter-ação 32, nº.2, (2007), https://doi.org/10.5216/ ia.v32i2.3049 (Consultado em 15 de setembro de 2020).

Xaxier, Maria C. coord. Manifesto dos pioneiros da educação. Um legado educacional em debate. Rio de Janeiro: Editora FGV. 2004. 